Article

\title{
Different Strategies for the Preparation of Galactose-Functionalized Thermo-Responsive Nanogels with Potential as Smart Drug Delivery Systems
}

\author{
Mirian A. González-Ayón ${ }^{1}$, Angel Licea-Claverie 1,*(D) and J. Adriana Sañudo-Barajas ${ }^{2}$ (D) \\ 1 Centro de Graduados e Investigación en Química, Tecnológico Nacional de México/Instituto Tecnológico de \\ Tijuana, Apartado Postal 1166, Tijuana 22454, Mexico; mirian.gonzalez@tectijuana.edu.mx \\ 2 Centro de Investigación en Alimentación y Desarrollo, A. C. Carretera a El dorado Km 5.5, \\ Culiacán 80110, Mexico; adriana@ciad.mx \\ * Correspondence: aliceac@tectijuana.mx
}

Received: 10 August 2020; Accepted: 4 September 2020; Published: 21 September 2020

check for updates

\begin{abstract}
Different synthetic strategies were tested for the incorporation of galactose molecules on thermoresponsive nanogels owing to their affinity for receptors expressed in cancer cells. Three families of galactose-functionalized poly( $N$-vinylcaprolactam) nanogels were prepared with the aim to control the introduction of galactose-moieties into the core, the core-shell interface and the shell. First and second of the above mentioned, were prepared via surfactant free emulsion polymerization (SFEP) by a free-radical mechanism and the third one, via SFEP/reversible addition-fragmentation chain transfer (RAFT) polymerization. Synthetic recipes for the SFEP/free radical method included besides $N$-vinylcaprolactam (NVCL), a shell forming poly(ethylene glycol) methyl ether methacrylate (PEGMA), while the galactose (GAL) moiety was introduced via 6-O-acryloyl-1,2,3,4-bis-O-(1-methyl-ethylidene)- $\alpha$-D-galactopiranose (6-ABG, protected GAL-monomer): nanogels I, or 2-lactobionamidoethyl methacrylate (LAMA, GAL-monomer): nanogels II. For the SFEP/RAFT methodology poly(2-lactobionamidoethyl methacrylate) as GAL macro-chain transfer agent (PLAMA macro-CTA) was first prepared and on a following stage, the macro-CTA was copolymerized with PEGMA and NVCL, nanogels III. The crosslinker ethylene glycol dimethacrylate (EGDMA) was added in both methodologies for the polymer network construction. Nanogel's sizes obtained resulted between 90 and $370 \mathrm{~nm}$. With higher content of PLAMA macro-CTA or GAL monomer in nanogels, a higher the phase-transition temperature $\left(\mathrm{T}_{\mathrm{VPT}}\right)$ was observed with values ranging from 28 to $46^{\circ} \mathrm{C}$. The $\varrho$-parameter, calculated by the ratio of gyration and hydrodynamic radii from static (SLS) and dynamic (DLS) light scattering measurements, and transmission electron microscopy (TEM) micrographs suggest that core-shell nanogels of flexible chains were obtained; in either spherical (nanogels II and III) or hyperbranched (nanogels I) form.
\end{abstract}

Keywords: thermoresponsive nanogels; RAFT; SFEP; $N$-vinylcaprolactam; galactose-functionalized nanogels

\section{Introduction}

Carbohydrates play a premier role in a myriad of biological processes [1,2]. With the increasing understanding of carbohydrates roles in biological systems, synthetic carbohydrate-based materials, particularly, glycopolymers, and glyco-nanoparticles, are now receiving enormous attention and have been the subject of intense research in the last few decades. There is a strong interest in the 
preparation of synthetic glycopolymers of well-defined structures, like nanogels and a wide range of other architectures, with compositions that can mimic biological functions, in a less complex environment [3]. Glycopolymers are synthetic polymers featuring pendant carbohydrate moieties. On the one hand, glycopolymers, owing to their biocompatibility and multivalence, play a vital role in many biological recognition processes such as: cell-cell adhesion [4,5], development of new tissues, and infectious behavior of virus and bacteria [6,7]. On the other hand, nanogels, specifically those sensitive to external stimuli such as temperature and $\mathrm{pH}$, are materials with a wide range of applications mainly in the biomedical area due to their excellent properties, such as biocompatibility and stability in aqueous mediums, for instance, for controlled release of drugs [8]. Moreover, due to their hydrophilic character, they are inert materials resulting in cells and proteins not tending to adhere to their surface. Additionally, their characteristic swelling in aqueous mediums, gives them the ability to absorb, retain, and release, under controlled conditions, some organic molecules (drugs) [9]. Therefore, with the advent of nanotechnology, nanoparticles containing sugar residues on the surface, also received a lot of attention, ranging from studies of carbohydrate/protein interactions $[10,11]$, carbohydrate/carbohydrate interactions [12-16], in vivo cell imaging [17,18], vaccine development, targeted drug delivery, and bioassays [19,20].

Several polymerization methods are available to prepare well-defined glycopolymers. Versatile reversible deactivation radical polymerization techniques such as atom-transfer radical polymerization (ATRP) [21] and reversible addition-fragmentation chain transfer (RAFT) [22-24] polymerization have been widely used for the engineering of complex polymeric architectures to synthesize well-defined glycopolymers. RAFT has attracted the attention of many polymer researchers as it allows the synthesis of biocompatible polymers with low dispersity index (Đ), high functionality and more important, the possibility to use unprotected glycomonomers. Different types of carbohydrates such as mannose [25], galactose [26], lactose [27], glucose [28] and dextrin [29] have been used as precursors for the preparation of glycopolymers. Specifically, galactose molecules have great potential in the nanoparticle glycosylation, due to their affinity for expression receptors in cancer cells. On the one hand, galactose-based polymers have been shown to have affinity for the overexpressed asialoglycoprotein (ASGP-R) in liver cancer [30], but also for the prometastatic protein galectin 3 (Gal3) over-expressed in prostate cancer [31], colon [32], breast cancer [33], melanoma [34], multiple myeloma [35] and hemangiosarcoma [36].

Temperature sensitive galactosylated nanoparticles based on poly( $N$-isopropylacrylamide) [37], poly(di(ethyleneglycol) methylether methacrylate) [38], and poly( $N, N$-dimethylaminoethyl methacrylate) [39], have been reported for affinity to ASGP-R receptor. Nevertheless, polymers based on $N$-vinylcaprolactam (NVCL) may become powerful anticancer drug carriers, given that they are also temperature-responsive, in addition to being very stable against hydrolysis, and biocompatible [40]. In previous reports, nanogels based on NVCL have shown to increases their response temperature $\left(\mathrm{T}_{\mathrm{VPT}}\right)$ when they were copolymerized with other monomers such as $N$-vinylpyrrolidone or poly(ethyleneglycol) methacrylate (PEGMA) [41-43]. In the present work, the synthesis of three families of galactosylated nanogels based on NVCL was studied. The preparation of Nanogels I and nanogels II was attempted by using surfactant free emulsion polymerization (SFEP) via a free-radical mechanism; while the preparation of nanogels III was attempted by SFEP via reversible addition-fragmentation chain transfer (RAFT) polymerization (Scheme 1). The galactose-functionality in the core, at the core-shell interface and at the shell of the nanogels was expected by means of using either a protected GAL-monomer 6-ABG, a GAL-monomer LAMA and a polyLAMA (PLAMA) macro-CTA, respectively. These, three core-shell nanogel types, are proposed as nanomaterials with potential use in the transport of anticancer drugs to target cancer cells due the Gal3-galactan affinity. 


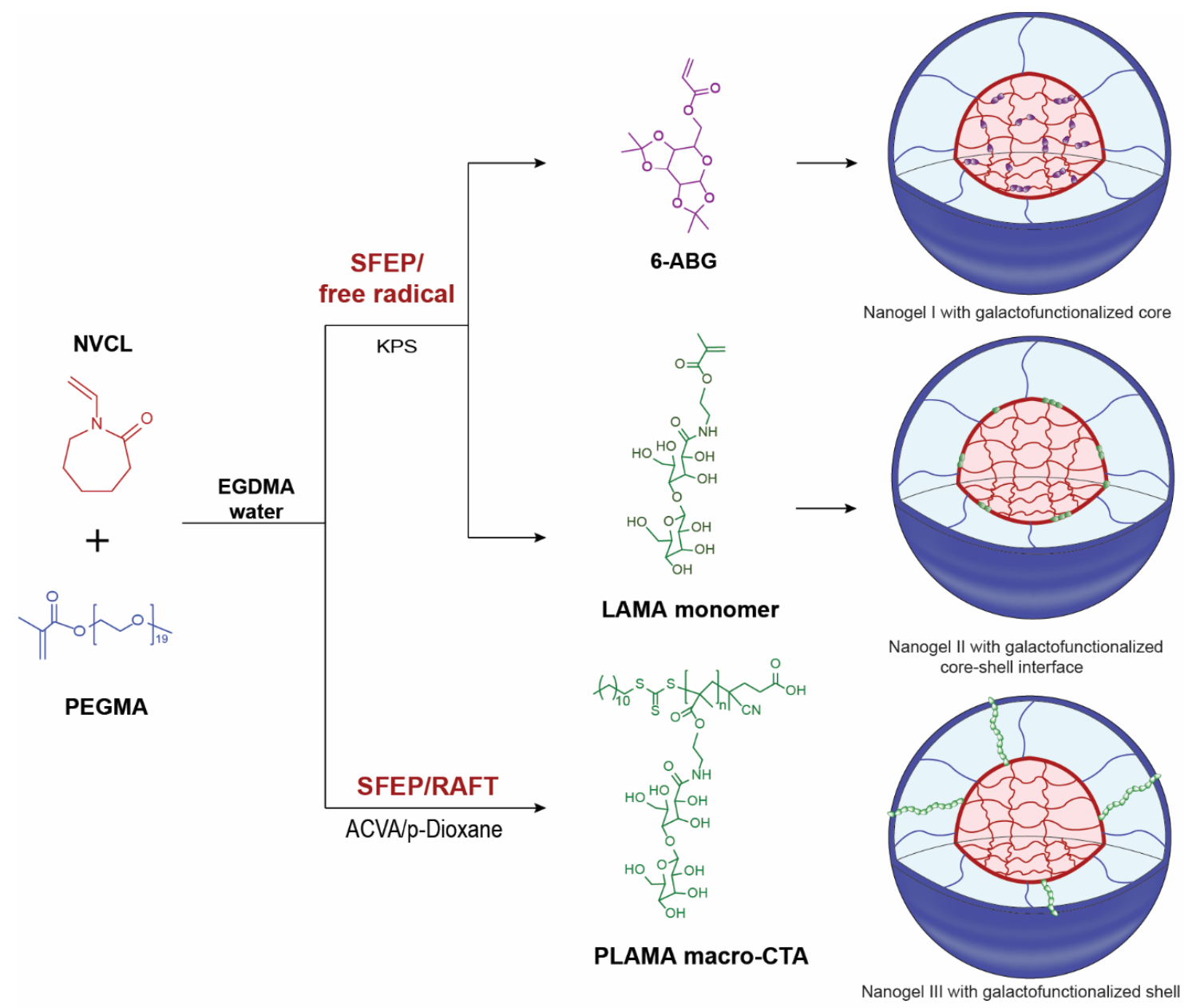

Scheme 1. Synthetic strategy for the preparation of PNVCL:PEGMA:GAL core-shell nanogels via $\mathrm{SFEP} /$ free radical polymerization (I and II) and via SFEP/RAFT polymerization (III).

\section{Materials and Methods}

\subsection{Materials}

4-Cyano-4(dodecylsulfanylthiocarbonyl)sulfanyl pentanoic acid (the RAFT chain transfer agent or CTA) was synthesized as described in literature [44]. Lactobionic acid (LA, 97\%), poly(ethylene glycol) methyl ether methacrylate (PEGMA, $\mathrm{M}_{\mathrm{n}}=950 \mathrm{~g} / \mathrm{mol}$ ), 4,4'-azobis(4-cyanovaleric acid) (ACVA), potassium persulfate (KPS, 98\%), ethylene glycol dimethacrylate (EGDMA, 98\%), and 6-O-acryloyl-1,2,:3,4-bis-O-(1-methyl-ethylidene)- $\alpha$-D-galactopiranose (6-ABG, 97\%) were used as received. $\mathrm{N}$-Vinylcaprolactam (NVCL, 98\%) was purified by recrystallization in hexane and dried under vacuum prior to use. All solvents, deuterated and non-deuterated, similarly to all reagents, were purchased from Sigma-Aldrich (Toluca, Mexico); with one exception, ethanol was provided by Fermont (Monterrey, Mexico). Commercial grade distilled water was used (Sparkletts, CA, USA).

\subsection{Synthesis of PLAMA-Macro CTA}

The monomer 2-lactobionamidoethyl methacrylate (LAMA) was synthesized according to previously reported protocols [44]. The synthesis of PLAMA macro-CTA was carried out by RAFT polymerization. A typical synthesis of PLAMA macro-CTA was conducted as follows. $0.5 \mathrm{~g}$ LAMA monomer and $0.036 \mathrm{~g}$ ACVA were dissolved in $8 \mathrm{~mL}$ of $\mathrm{H}_{2} \mathrm{O}: \mathrm{EtOH}$ (9:1), simultaneously the CTA $(0.145 \mathrm{~g})$ was dissolved in THF $(1 \mathrm{~mL})$ and then both were mixed inside an ampoule containing a magnetic stir-bar (Scheme S1 in the Supplementary Materials file:SM). Oxygen was removed of the 
reaction mixture by freeze-thaw cycles in Argon atmosphere and the ampoule was sealed using a torch. After that, the monomer solution was heated to $70{ }^{\circ} \mathrm{C}$ in a preheated oil bath maintaining constant magnetic stirring for 16 and $24 \mathrm{~h}$. After the desired polymerization time the reaction was stopped by cooling with ice-water. Finally, the product was isolated by precipitation in cold acetone, filtered-off and dried in vacuum at room temperature. Two PLAMA macro-CTAs were obtained, one polymerized for $16 \mathrm{~h}$ and the second one for $24 \mathrm{~h}$.

\subsection{Synthesis of PNVCL:PEGMA Galactosilated Nanogels I and II via SFEP/Free Radical Polymerization}

Two types of galactosylated PNVCL:PEGMA:GAL nanogels were synthesized by surfactant free emulsion polymerization (SFEP) via free radical mechanism. The reaction was carried out in a schlenk flask containing a magnetic stir-bar connected to a nitrogen inlet using quantities described in Table S1 in SM. In the first one (nanogels I), the protected GAL-monomer 6-O-acryloyl-1,2,:3,4-bis-O-(1-methyl-ethylidene)- $\alpha$-D-galactopiranose (6-ABG) was added to the reaction mixture in water containing NVCL, PEGMA and EGDMA and stirred strongly but avoiding the formation of foam. For the second one (nanogels II), the GAL-monomer LAMA was added instead of 6-ABG. One example follows: $N$-vinylcaprolactam $(0.3 \mathrm{~g}, 2.16 \mathrm{mmol})$, PEGMA ( $0.2 \mathrm{~g}, 0.21 \mathrm{mmol})$, and EGDMA $(12.2 \mu \mathrm{L}, 0.0128 \mathrm{~g}, 0.065 \mathrm{mmol})$ were dissolved in $48 \mathrm{~mL}$ of deionized water. At the same time, the initiator KPS $(0.075 \mathrm{~g}, 0.277 \mathrm{mmol})$ was dissolved in $2 \mathrm{~mL}$ of deionized water, too. The reaction mixture containing NVCL, PEGMA, EGDMA and LAMA was bubbled with nitrogen for 30 $\min$ to remove the oxygen present. Subsequently, the mixture was placed in a preheated oil bath at $85^{\circ} \mathrm{C}$ for $20 \mathrm{~min}$ under strong stirring; and afterwards, the initiator (KPS) was added to initiate the polymerization reaction (Scheme 1). The reaction was stopped by freezing after $1 \mathrm{~h}$. In all reactions the products were purified via dialysis against distilled water for 5 days, using Spectra/Por dialysis membrane with MWCO = 12000-14000 Da, performing water changes twice daily. Samples were frozen and lyophilized on a Labconco Freeze Dry System Freezone 4.5 (Kansas City, MI, USA). Then, the samples were stored in a refrigerator until use.

\subsection{Synthesis of PNVCL:PEGMA Galactosilated Nanogels III vía SFEP/RAFT Polymerization}

The synthesis of nanogels via SFEP/RAFT polymerization was carried out using quantities described in Table S1 in SM. Water was used as medium of polymerization, primarily. In this way, it can be considered that Nanogel III was prepared similarly to those obtained by SFEP/free radical polymerization, one example follows: $N$-vinylcaprolactam $(0.3 \mathrm{~g}, 2.16 \mathrm{mmol})$, PEGMA $(0.2 \mathrm{~g}$, $0.21 \mathrm{mmol})$, EGDMA $(12.2 \mu \mathrm{L}, 0.0128 \mathrm{~g}, 0.065 \mathrm{mmol})$ were dissolved in $48 \mathrm{~mL}$ of deionized water, while the PLAMA macro-CTA $(0.096 \mathrm{~g}, 0.053 \mathrm{mmol})$ and ACVA $(0.024 \mathrm{~g}, 0.086 \mathrm{mmol})$ were dissolved in $1 \mathrm{~mL}$ of $p$-dioxane each. Then the procedure of mixing and degassing was followed as described before. The reaction temperature was $70^{\circ} \mathrm{C}$ and was stopped by freezing after $24 \mathrm{~h}$. In all reactions the resulting products were purified and stored similarly to nanogels I and II.

\subsection{Hydrodynamic Diameter, Sensitivity to Temperature and Zeta Potential}

To analyze size distributions of the nanogels obtained, dynamic light scattering (DLS) was used on a Malvern Instruments Zetasizer Nano-ZS (ZEN 3690), (Malvern, Worcestershire, UK) equipped with a red laser $(630 \mathrm{~nm})$ and a measurement detector at $90^{\circ}$. For this characterization, purified and re-dispersed materials were used. The concentration employed was $1 \mathrm{wt} \%$ of nanogels in deionized water. The size distribution by intensity using CONTIN analysis is reported. The hydrodynamic diameters $\left(D_{h}\right)$ were calculated using the hydrodynamic radius $\left(R_{h}\right)$ calculation from the Stokes-Einstein equation for spheres (Equation (1)).

$$
R_{h}=\frac{k T}{6 \pi \eta_{0} D}
$$

where $k$ is the Boltzmann constant, $T$ is the absolute temperature, $\eta_{0}$ is the solvent viscosity, and $D$ is the diffusion coefficient determined from DLS data. 
Using the same equipment, the response temperature $\left(\mathrm{T}_{\mathrm{VPT}}\right)$ of the nanogels was analyzed by DLS. The effect of temperature on the particle size was studied using dispersions at $1 \mathrm{mg} \mathrm{mL}^{-1}$ of nanogels in water while the temperature was varied from 20 to $50{ }^{\circ} \mathrm{C}$ with 4 min of equilibration time between each temperature value. The reported $T_{V P T}$ is taken as the minimum of the derivative of $\mathrm{dD}_{\mathrm{h}} / \mathrm{dT}$.

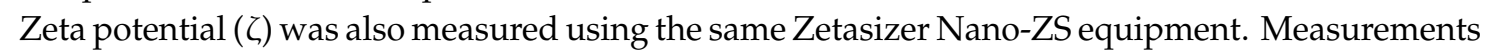
were performed on folded capillary cells at $25^{\circ} \mathrm{C}$ adjusting the $\mathrm{pH}$ of the medium from 5 to 8 . Reported values were the average of three runs.

\subsection{Molecular Weight, Radius of Gyration, and Second Virial Coefficient}

To determine the weight-average molecular weight $\left(M_{w}\right)$, radius of gyration $\left(R_{g}\right)$, and second virial coefficient $\left(A_{2}\right)$, of the nanogels, a static light scattering (SLS) method was used. The equipment employed was a Goniometer from Brookhaven Instruments (Holtsville, NJ, USA) model BI-200SM-E multi-angle DLS/SLS with digital autocorrelator TurboCorr. Concentrations of nanogels in water, for these measurements were $0.1,0.15,0.25,0.35$, and $0.5 \mathrm{mg} \mathrm{mL}^{-1}$ and the measurement angles were selected from $30^{\circ}$ to $150^{\circ}$. The Berry plot algorithm was applied for the evaluation of results, using Equation (2).

$$
\left(\frac{K C}{R_{\theta}}\right)^{0.5}=\left(\frac{1}{M_{w}}\right)^{0.5}\left(1+\frac{q^{2} R_{g}^{2}}{6}\right)\left(1+A_{2} M_{w} C\right)
$$

where $K$ is an optical constant independent of the concentration of the solution and the molecular weight of the polymer, $C$ is the nanogels concentration, $R_{\theta}$ is the normalized scattering intensity (Rayleigh ratio) at the scattering angle $\theta, M_{w}$ is the weight-average molecular weight, $R_{g}$ is the radius of gyration, $A_{2}$ is the second virial coefficient, and $q$ is the magnitude of the scattering vector, expressed as $q=(4$ $\left.\mathrm{p} n / \lambda_{0}\right) \sin (\theta / 2)$, with $n$ and $\lambda_{0}$, being the solvent refractive index, and the laser wavelength, respectively.

\subsection{Chemical Structure and Composition}

Fourier transform infrared spectroscopy (FT-IR) was used to analyze the chemical structure of nanogels using a Spectrum 400, FT-IR/FT-NIR Spectrometer (Perkin Elmer Cetus Instruments, Norwalk, CT, USA) with a diamond attenuated total reflection (ATR) accessory in the spectral range from 4000 to $650 \mathrm{~cm}^{-1}$. The samples were used directly as dried powders and 16 scans were collected.

The chemical composition of nanogels was evaluated by hydrogen nuclear magnetic resonance spectroscopy $\left({ }^{1} \mathrm{H}-\mathrm{NMR}\right)$ using a Bruker AVANCE III HD NMR $400 \mathrm{MHz}$ equipment (Billerica, MA, USA). Dried nanogels of known weight $(20 \mathrm{mg})$ were dispersed in deuterated chloroform $\left(\mathrm{CDCl}_{3}\right)$ $(600 \mu \mathrm{L})$ or dimethyl sulfoxide- $\mathrm{d}_{6}\left(\right.$ DMSO- $\left._{6}\right)(600 \mu \mathrm{L})$ using an ultrasonic bath for 10 min keeping the dispersion cold.

\subsection{Morphological Analyses}

Transmission electron microscopy micrographs (TEM) were acquired using a H7500 transmission electron microscope (Hitachi Co. Ltd., Tokyo, Japan) operating at an accelerating voltage of $80 \mathrm{kV}$. Samples were prepared by dispersing $0.5 \mathrm{mg}$ of nanogels in $1 \mathrm{~mL}$ of water under stirring for $48 \mathrm{~h}$. A drop of those dispersions was poured over a 75-mesh nickel grid coated with a thin layer of carbon/collodion followed by removing excess liquid at room temperature. Afterwards, the samples were stained using a $1 \%$ uranyl acetate solution for $1 \mathrm{~min}$.

\section{Results and Discussion}

\subsection{Synthesis of PLAMA-Macro CTA}

The formation of the LAMA monomer was verified by FT-IR and ${ }^{1} \mathrm{H}-\mathrm{NMR}$ (Figures S1 and S2 in SM), and the product was obtained with a yield above $90 \%$. In the case of PLAMA-macro CTA, both products (obtained after 16 and $24 \mathrm{~h}$ of reaction) were pure, as shown in the ${ }^{1} \mathrm{H}-\mathrm{NMR}$ spectrum 
(Figure 1). The hydrogen $f$ corresponds to the -NH at $7.83 \mathrm{ppm}$, the signal $d$ at $4.74 \mathrm{ppm}$ corresponds to the methylene attached to oxygen of ester of LAMA and the signal $a$ at 2.09 ppm corresponds to the methyl hydrogens of LAMA. The signal at $0.86 \mathrm{ppm}$ corresponds to the methyl terminal group of the CTA, with an integration of 3. According to the integrations obtained for each macro-CTA at $0.86 \mathrm{ppm}$ in relation to the signal at $2.09 \mathrm{ppm}$, it was possible to estimate the molecular weight of the obtained macro-CTAs, being 1342 and 1812 Da for 16 and $24 \mathrm{~h}$ of reaction time, respectively.

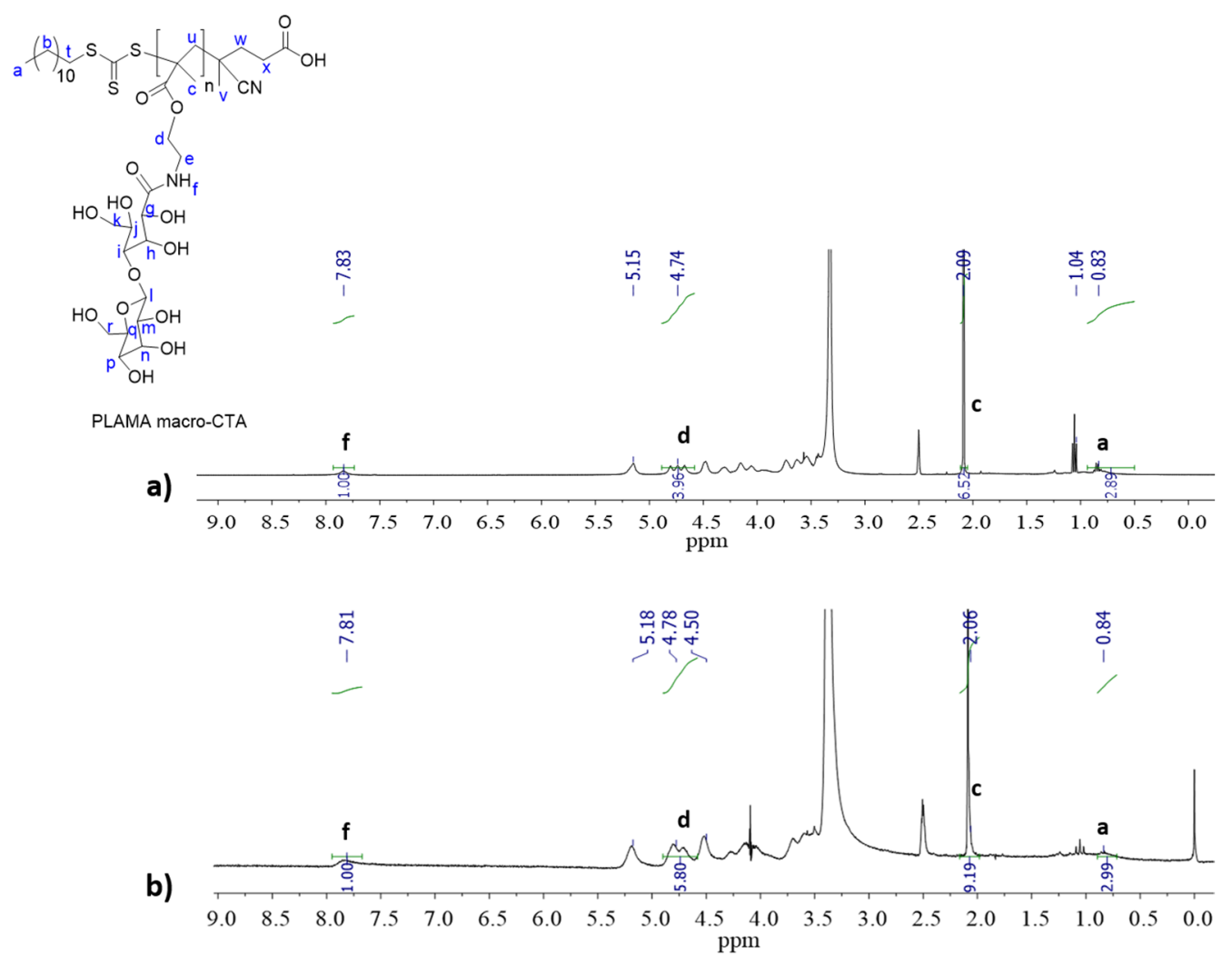

Figure 1. ${ }^{1} \mathrm{H}-\mathrm{NMR}$ spectrum of PLAMA macro-CTA obtained at different polymerization times: (a) $16 \mathrm{~h}$ with $1342 \mathrm{Da}$, and (b) $24 \mathrm{~h}$ with $1812 \mathrm{Da}$.

\subsection{Synthesis of PNVCL:PEGMA Galactosylated Nanogels via SFEP/Free Radical or SFEP/RAFT Methods}

For galactose-functionalized nanogels prepared via SFEP/free radical methods, either 6-ABG (nanogels I) or LAMA (nanogels II) were used as GAL-based monomers, also NVCL, PEGMA and EGDMA were added to the synthesis recipe, while potassium persulfate (KPS) was used as free-radical initiator. On the other hand, the PLAMA macro-CTA was used for the preparation of galactose-functionalized nanogels III via SFEP/RAFT polymerization with NVCL, PEGMA and EGDMA; the free-radical initiator was 4,4,-azo-bis(4-cyano valeric acid) (ACVA). In both types of polymerizations, the reactions were carried out similarly in distilled water. The content of each ingredient in the different synthetic recipes is shown in the Supporting Information file (Table S1 in SM).

In the case of nanogels prepared via SFEP/free radical polymerization, an aqueous system including NVCL, PEGMA and crosslinker EGDMA was used, the GAL moiety was introduced either via protected, less hydrophilic, GAL-monomer 6-ABG (nanogels I) or via water soluble unprotected, highly hydrophilic GAL-monomer LAMA (nanogels II). KPS was used as initiator. A reaction temperature of $85^{\circ} \mathrm{C}$ was used; well above the lower critical solution temperature (LCST) of the corresponding linear PNVCL polymer in water. At this temperature, the polymer initially formed, turns hydrophobic but does not precipitates, since it is stabilized by the hydrophilic comonomer PEGMA, forming a stable nucleus progressively crosslinked with EGDMA, leading to nanogel formation. Since LAMA is highly water soluble, it copolymerizes with NVCL but tends to grow in the interface between 
hydrophobic PNVCL-core and hydrophilic PEGMA-shell; while in the case of 6-ABG being less hydrophilic, it is expected that it is copolymerized with NVCL in the core of the nanogel.

The SFEP/RAFT copolymerization in water allows, theoretically, the preparation of core-shell nanogels, similarly to a SFEP/free-radical mechanism, with controlled size, molecular weight, and responsive behavior. A reaction temperature of $70^{\circ} \mathrm{C}$ was used; forming NVCL:PEGMA stable nucleus progressively crosslinked with EGDMA and controlled by the hydrophilic macro-CTA employed, leading to nanogel formation. Since PEGMA contains a polymerizable methacrylate end-group and the PLAMA macro-CTA is hydrophilic, they are chemically attached to the nanohydrogels forming a PEG/GAL shell in nanogels III [42,45]. This strategy to obtain temperature-responsive nanogels takes advantage of the polymerization induced thermal self-assembly and stabilization of the forming nanoparticles [46,47], while the macro-CTA controls the polymerization rate. In all systems, the conversions were determined gravimetrically and resulted to be similar, between 52 and $55 \%$ (see data in Table S1 in SM).

The nanogel sizes were analyzed by dynamic light scattering (DLS). DLS-data showed unimodal distributions as observed in Figure 2, for nanogels with different content of GAL (6-ABG monomer, LAMA monomer or PLAMA macro-CTA). On the one hand, it is reported in literature that the preparation of core-shell nanogels is well-controlled based on size and polydispersity by surfactant free emulsion polymerization [41,46]. The SFEP/free radical method used in this report was adapted from previous reports on PNVCL nanogels [41,42]. Two groups of nanogels by SFEP/free radical polymerization were synthesized: In the first one, a protected GAL-monomer (6-ABG) was used, to form nanogels with a core containing galactose molecules; while in the second one, a free galactose (LAMA) monomer was added to the reaction mixture, to obtain a GAL-functionalized interface between core and shell. The nomenclature assigned for the nanogels I group was: $\mathrm{NVCL}_{37 \cdot 5 \mathrm{wt} \%}: \mathrm{PEGMA}_{25 \mathrm{wt} \%}: 6-\mathrm{ABG}_{37 \cdot 5 \mathrm{wt} \%}(\mathrm{~N} 46), \mathrm{NVCL}_{46 \mathrm{wt} \%}: \mathrm{PEGMA}_{31 \mathrm{wt} \%}: 6-\mathrm{ABG}_{23 \mathrm{wt} \%}$ (N45) and $\mathrm{NVCL}_{52 \mathrm{wt} \%}: \mathrm{PEGMA}_{35 \mathrm{wt} \%}: 6-\mathrm{ABG}_{13 \mathrm{wt} \%}(\mathrm{~N} 48)$; and for the nanogels II group was: $\mathrm{NVCL}_{46 \mathrm{wt} \%}: \mathrm{PEGMA}_{31 \mathrm{wt} \%}: \mathrm{LAMA}_{23 \mathrm{wt} \%}$ (N50) and NVCL ${ }_{51 \mathrm{wt} \%}: \mathrm{PEGMA}_{34 \mathrm{wt} \%}: \mathrm{LAMA}_{15 \mathrm{wt} \%}(\mathrm{~N} 51)$.
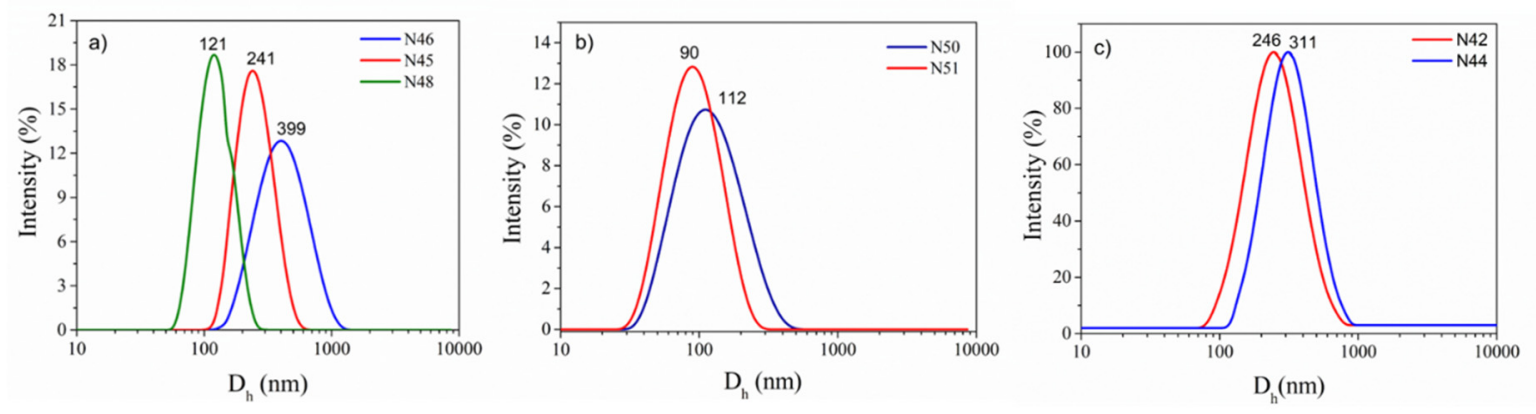

Figure 2. Size distributions by DLS for nanogels: (a) NVCL:PEGMA:6-ABG (SFEP/free radical nanogels I, protected GAL); (b) NVCL:PEGMA:LAMA (SFEP/free radical nanogels II, GAL), and (c). NVCL:PEGMA:PLAMA macro-CTA (SFEP/RAFT nanogels III, GAL macro-CTA).

The size of nanogels by SFEP was analyzed by DLS, and narrow unimodal distributions were obtained. For the first group of nanogels (galactosylated core) the higher content of 6-ABG monomer the bigger hydrodynamic diameter was obtained. It has been reported that for SFEP using PEGMA as a polymerizable stabilizer, the lower the amount of PEGMA, the higher the nanogels diameter obtained [46]. In our case, this behavior is also present, since the higher content on GAL monomer concomitantly leads to a lower amount of PEGMA stabilizer in the synthetic recipe resulting in nanogels with larger size. Nanogels I with 13, 23 and $37.5 \mathrm{wt} \%$ of 6-ABG monomer in the reaction mixture, showed $D_{h}$ values of 121, 241 and $399 \mathrm{~nm}$, respectively (Figure 2a); while nanogels II with $23 \%$ and $15 \%$ of LAMA monomer the diameters measured were 112 and $90 \mathrm{~nm}$ (Figure 2b). In the case of the second group (galactosylated core-shell interface), the results showed a noticeable trend in size growth 
by increasing the amount of LAMA monomer in the reaction; this can be attributed to the formation of hydrogen bonds between these monomers and the dispersing water, which causes the nanogels to be mostly swollen. Furthermore, as the weight fraction of GAL monomer increased, the growing polymer chains become more hydrophilic during the polymerization; thus, bigger hydrophobic cores formed by PNVCL, could be stabilized easily with the poly(LAMA-co-PEGMA) hydrophilic chains $[48,49]$.

In the case of SFEP/RAFT nanogels III, it can also be observed that the increase in the GAL concentration from 15 to $23 \mathrm{wt} \%$, results in smaller hydrodynamic diameters $\left(D_{h}\right)(311$ to $246 \mathrm{~nm}$, respectively) (Figure 2c). Concomitantly, the polydispersity calculated from the cumulant method (PDI $=\mu_{2} / \Gamma^{2}$ ), increases while increasing the GAL (PLAMA macro-CTA) concentration from 0.18 to 0.33 for 15 to $23 \mathrm{wt} \%$ of GAL in the feed. Via SFEP/RAFT, the nomenclature used was specified according to the

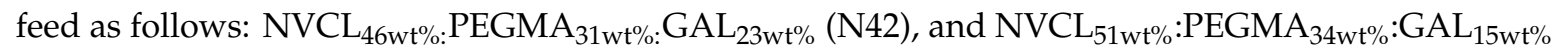
(N44), where the GAL content evolves from the PLAMA macro-CTA used in different amounts. An explanation for this behavior can be found if the PLAMA-macro-CTA is considered as an additional stabilizer to the PEGMA in the synthetic recipe for the growing PNVCL block forming the core. A higher amount of stabilizer to a lower core-forming monomer amount result in an overall smaller nanogel.

Molecular weight $\left(M_{w}\right)$, radius of gyration $\left(R_{g}\right)$ and the second virial coefficient $\left(A_{2}\right)$ data, were determined by static light scattering (SLS). The Berry plot for sample N45, measured in water at 25 ${ }^{\circ} \mathrm{C}$ (Figure 3), showed a linear dependence on the scattering angle, and was related to homogeneous particles [50,51]. Data from SLS and DLS are summarized in Table 1 (Figures S3-S9 in SM). Nanogels show $\mathrm{M}_{\mathrm{W}}$ values between $3.65 \times 10^{6}$ and $2.20 \times 10^{10} \mathrm{~g} \mathrm{~mol}^{-1}$ and $\mathrm{R}_{\mathrm{g}}$ values between 44 and $210 \mathrm{~nm}$. Values of $\mathrm{A}_{2}$ are between $2.01 \times 10^{-9}$ and $1.18 \times 10^{-4}$ and indicate a good interaction between nanogels and water. The shape factor, $\rho$-parameter, was calculated by the ratio between $R_{g}$ and $R_{h}$ (Table 1 ). The values obtained, show microgel/hard sphere morphology for nanogels N42 and N50, soft sphere for N44, N32 and N51; and star type morphology for N46, N45 and N48, in accordance to values reported by W. Burchard [52]. The nanogels N46, N45 and N48 are the ones prepared using the GAL protected monomer. The $\rho$-parameter results suggests that, despite the actual size of the products, nanogels prepared with this comonomer (6-ABG) incorporate the GAL-protected moiety in the core statistically mixed with NVCL polymers, while PEGMA chains are presumably located in a stabilizing shell.

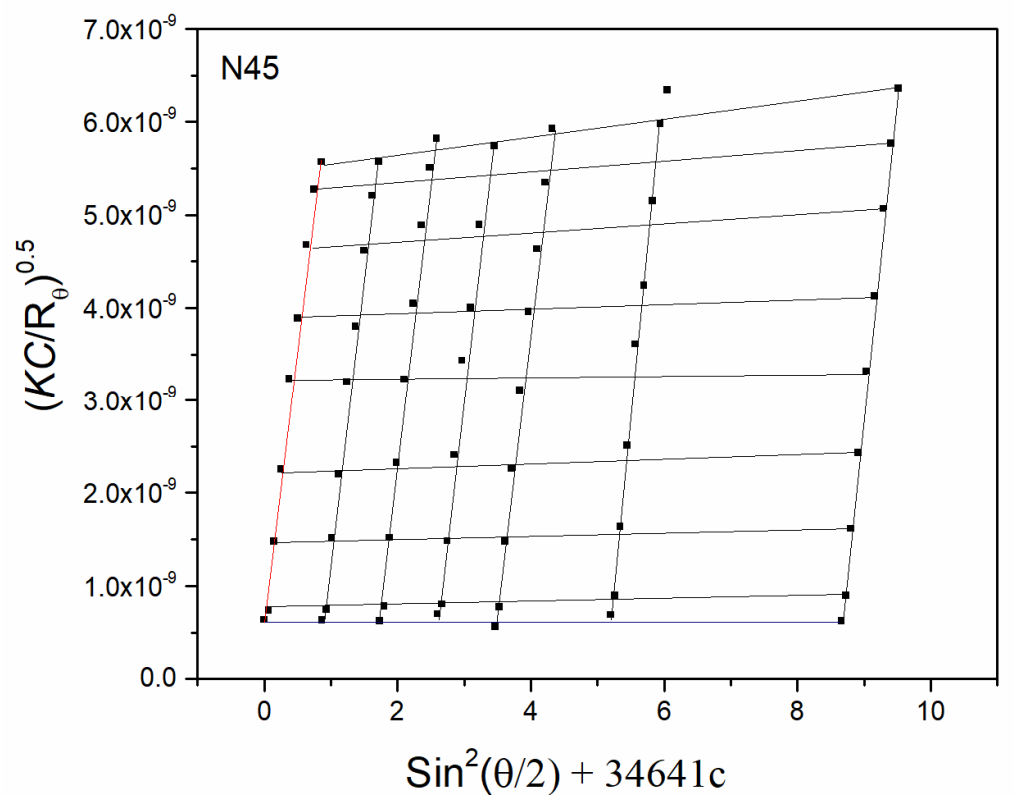

Figure 3. Berry plot of nanogel N45 obtained by SLS. 
Table 1. Light scattering data of nanogels prepared by SFEP (free radical and RAFT).

\begin{tabular}{|c|c|c|c|c|c|c|}
\hline Nanogel & $\mathrm{R}_{\mathrm{h}}{ }^{\mathrm{a}}(\mathrm{nm})$ & PDI $^{a}$ & $\begin{array}{c}M_{w}^{b} \\
\left(\mathrm{~g} \mathrm{~mol}^{-1}\right)\end{array}$ & $\begin{array}{l}R_{g} b \\
(n m)\end{array}$ & $\begin{array}{c}\mathrm{A}_{2}{ }^{b} \\
\left(\mathrm{~mol} \mathrm{~mL} \mathrm{~g}^{-2}\right)\end{array}$ & $\rho$-Parameter ${ }^{c}$ \\
\hline \multicolumn{7}{|l|}{ Nanogels I } \\
\hline N46 & 185 & 0.14 & $2.20 \times 10^{10}$ & 210 & $3.75 \times 10^{-7}$ & 1.13 \\
\hline N45 & 120 & 0.11 & $1.57 \times 10^{9}$ & 173 & $2.01 \times 10^{-9}$ & 1.44 \\
\hline N48 & 61 & 0.08 & $8.74 \times 10^{8}$ & 76 & $4.83 \times 10^{-7}$ & 1.24 \\
\hline \multicolumn{7}{|l|}{ Nanogels II } \\
\hline N32 & 145 & 0.37 & $1.11 \times 10^{8}$ & 143 & $2.64 \times 10^{-6}$ & 0.98 \\
\hline N50 & 56 & 0.19 & $3.65 \times 10^{6}$ & 44 & $4.12 \times 10^{-6}$ & 0.78 \\
\hline N51 & 45 & 0.18 & $3.53 \times 10^{6}$ & 43 & $4.01 \times 10^{-6}$ & 0.95 \\
\hline \multicolumn{7}{|l|}{ Nanogels III } \\
\hline N42 & 144 & 0.33 & $9.10 \times 10^{6}$ & 112 & $1.18 \times 10^{-4}$ & 0.78 \\
\hline N44 & 156 & 0.18 & $7.90 \times 10^{7}$ & 154 & $2.50 \times 10^{-6}$ & 0.98 \\
\hline
\end{tabular}

Figure 4 shows TEM-micrographs of one example of each type of synthesized nanogels. Despite the differences in sizes, it is clear that the shape of the nanogels is more irregular in those synthesized using the protected GAL-monomer (6-ABG); coincidently with the light scattering results of $\rho$-parameter. Additional TEM-micrographs can be found in the Supporting Information file (Figures S10-S14 in SM).
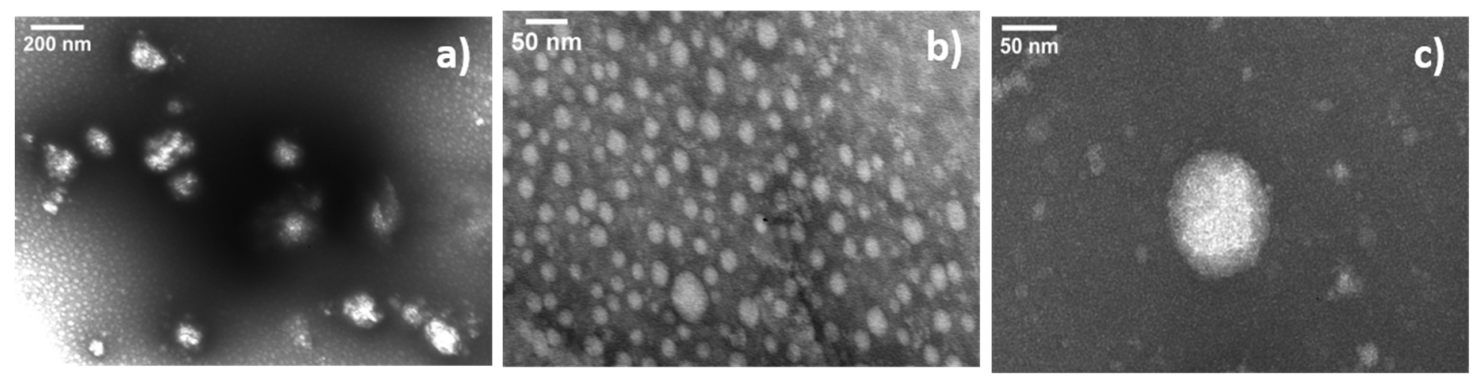

Figure 4. TEM micrographs of selected nanogels: (a) N46 (SFEP/free radical, 6-ABG); (b) N51 (SFEP/free radical, LAMA); (c) N44(SFEP/RAFT, PLAMA).

The actual content on NVCL, PEGMA and GAL in the respective synthesized nanogels was determined by hydrogen nuclear magnetic resonance $\left({ }^{1} \mathrm{H}-\mathrm{NMR}\right)$. Figure 5 shows the ${ }^{1} \mathrm{H}-\mathrm{NMR}$ spectrum of N42 as an example. The signal at $3.51 \mathrm{ppm}$ is assigned to the $-\mathrm{CH}_{2} \mathrm{CH}_{2}-\mathrm{O}\left(\mathrm{g}^{\prime}\right)$ of PEGMA lateral chain; the signal at $4.15 \mathrm{ppm}$ corresponds to $-\mathrm{CH}-(\mathrm{b})$ of the backbone of the PNVCL; the signal at 7.85 ppm is assigned to $\mathrm{N}-\mathrm{H}$ (i) of the PLAMA macro-CTA. The composition was calculated by integration of signals at chemical shifts of $3.51 \mathrm{pm}$ (PEGMA), $4.15 \mathrm{ppm}$ (NVCL) and $7.85 \mathrm{ppm}$ (macro-CTA, LAMA). ${ }^{1} \mathrm{H}-\mathrm{NMR}$ spectra of the other nanogels are included in the Supplementary information file (Figures S15-S21 in SM). Table 2 summarizes the compositions of nanogels, which proofs that PEGMA, NVCL and GAL are present in the produced nanogels structure. In general, NVCL content in products is lower than in the feed, while PEGMA and GAL content is higher than expected; since data indicated a preferred incorporation of comonomers over NVCL in the polymer network. This is a result of the different polymerization kinetics of NVCL and the other comonomers. NVCL is a monomer of the family of vinylamides, similar to vinylacetate (VAc), and its polymerization is rapid if initiated by radicals. However, in radical copolymerization, its propagating radical is not stable. 


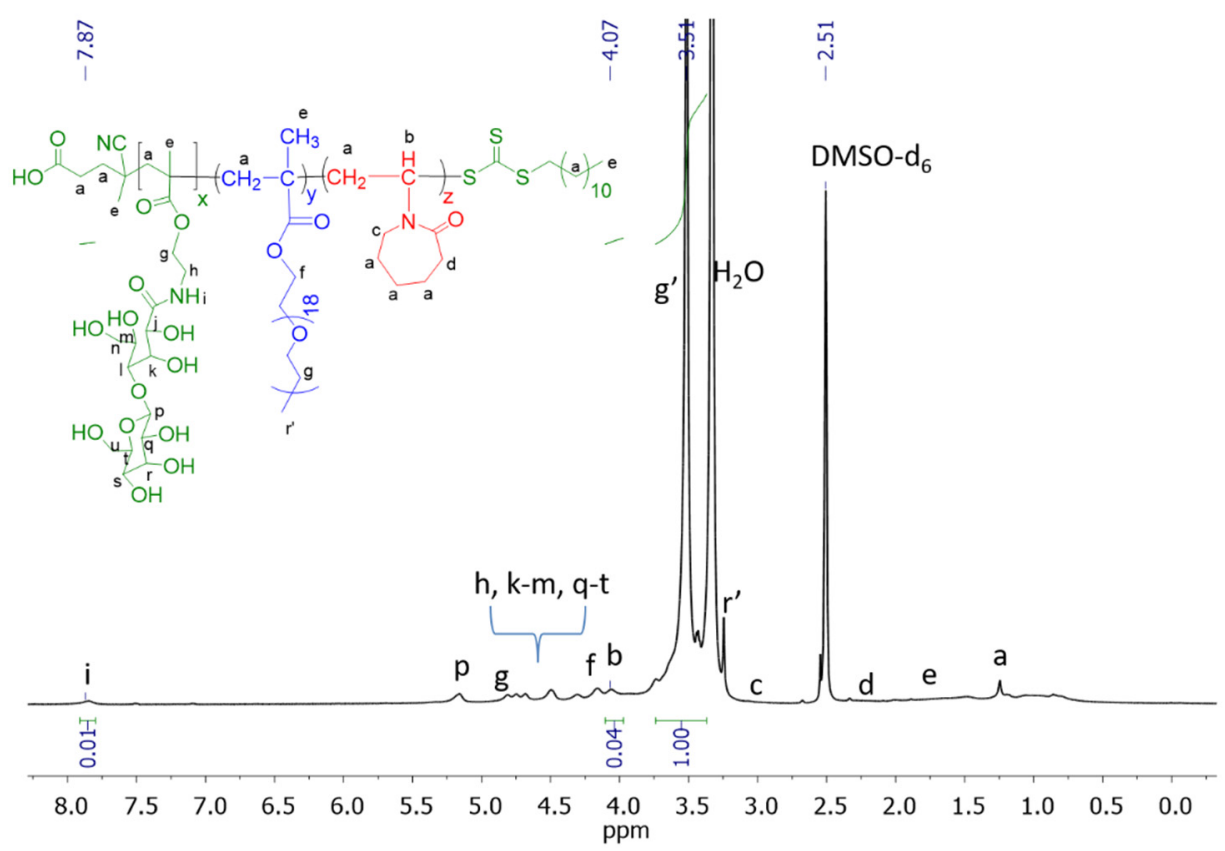

Figure 5. ${ }^{1} \mathrm{H}-\mathrm{NMR}$ spectrum of galactosylated nanogel N42 by RAFT.

Table 2. Composition of nanogels prepared by SFEP (free radical and RAFT) as determined by ${ }^{1} \mathrm{H}-\mathrm{NMR}$.

\begin{tabular}{|c|c|c|c|c|c|c|}
\hline \multirow[t]{2}{*}{ Nanogel } & \multicolumn{3}{|c|}{$\begin{array}{l}\text { Feed Composition } \\
(\mathrm{mol} \%)^{a}\end{array}$} & \multicolumn{3}{|c|}{$\begin{array}{l}\text { Product Composition } \\
\qquad(\mathrm{mol} \%)^{\mathrm{a}}\end{array}$} \\
\hline & NVCL & PEGMA & GAL & NVCL & PEGMA & GAL \\
\hline \multicolumn{7}{|l|}{ Nanogels I } \\
\hline N46 & 66.7 & 5.5 & 27.8 & 65.5 & 6.5 & 28.1 \\
\hline N45 & 76.9 & 6.3 & 16.8 & 65.3 & 7.6 & 27.2 \\
\hline N48 & 83.9 & 6.9 & 9.2 & 59.6 & 16.6 & 23.8 \\
\hline \multicolumn{7}{|l|}{ Nanogels II } \\
\hline N32 & 92.2 & 7.8 & 0 & 92 & 8 & 0 \\
\hline N50 & 80.3 & 7.8 & 11.9 & 65.4 & 26.9 & 7.7 \\
\hline N51 & 85.4 & 8.3 & 6.3 & 67.9 & 26.4 & 5.7 \\
\hline \multicolumn{7}{|l|}{ Nanogels III } \\
\hline N42 & 86.0 & 10.3 & 3.7 & 56.6 & 24.5 & 18.9 \\
\hline N44 & 88.3 & 8.4 & 3.3 & 76 & 12 & 12 \\
\hline
\end{tabular}

a The EGDMA content was not considered.

Therefore, if the second comonomer forms a more stable propagating specie, e.g., methacrylate radical, then NVCL will copolymerize sluggishly, favoring the incorporation of a more stable (methacrylate) comonomer [40]. Although, there are no reports on copolymerization parameters of NVCL and PEGMA in water, which could explain the copolymerization behavior, there is a report on NVCL with methyl methacrylate (MMA) prepared by microemulsion; the copolymerization parameters are $\mathrm{r}_{1}=0.25$ (for NVCL) and $\mathrm{r}_{2}=2.63$ (for MMA) evidencing the mismatch in copolymerization reactivity leading to lower amounts of NVCL in the copolymers than in the feed [53]. As a conclusion, it is not surprising that in our case, the NVCL monomer is incorporated in all three cases in lower amount than in the feed given the kinetics of NVCL copolymerization with methacrylates. The amount of GAL moieties in the nanogels prepared, from $5.7 \%$ to $28 \%$ is in the same order of magnitude as in other reports on galactose functionalized nanogels in literature [37] and most likely is enough for targeting purposes.

It was important to determine the effect of incorporation of the GAL comonomer in the nanogels thermosensitive behavior. The effect of temperature on the galactosylated nanohydrogel size 
dispersed in water was analyzed by DLS. Usually, temperature sensitive polymer networks based on LCST/polymers are swollen below the volume phase transition temperature $\left(\mathrm{T}_{\mathrm{VPT}}\right)$ and shrink above it. The $\mathrm{T}_{\mathrm{VPT}}$ was estimated from the first derivative of hydrodynamic diameter measured at different temperatures. The results for some nanogels are shown in Figure 6. A nanogel without GAL monomer (nanogel N32) serves as a blank nanomaterial for comparison purposes (Figure 6a), this nanogel shows a transition temperature at $28^{\circ} \mathrm{C}$, a temperature too low for biomedical applications. In the case of the SFEP/RAFT nanogels containing GAL, N44 (Figure S22 in SM) and N42 (Figure 6c), they showed an increase on the $\mathrm{T}_{\mathrm{VPT}}$ values from 40 to $43^{\circ} \mathrm{C}$, as the concentration of the galactose PLAMA macro-CTA increases from $12 \%$ to $18.9 \mathrm{~mol} \%$. It is well known that for thermoresponsive copolymers showing a LCST, the presence of a hydrophilic comonomer can increase the $\mathrm{T}_{\mathrm{VPT}}$, while the increase of concentration of the thermosensitive monomer decrease the $\mathrm{T}_{\mathrm{VPT}}$ to the homopolymer's original value [54]. This phenomenon can be attributed once again to the formation of hydrogen bonds between GAL and the environment (water), requiring a higher energy (temperature) to break those interactions and induce a coil to globule transition of the individual chains, resulting in shrinkage of the nanogels.
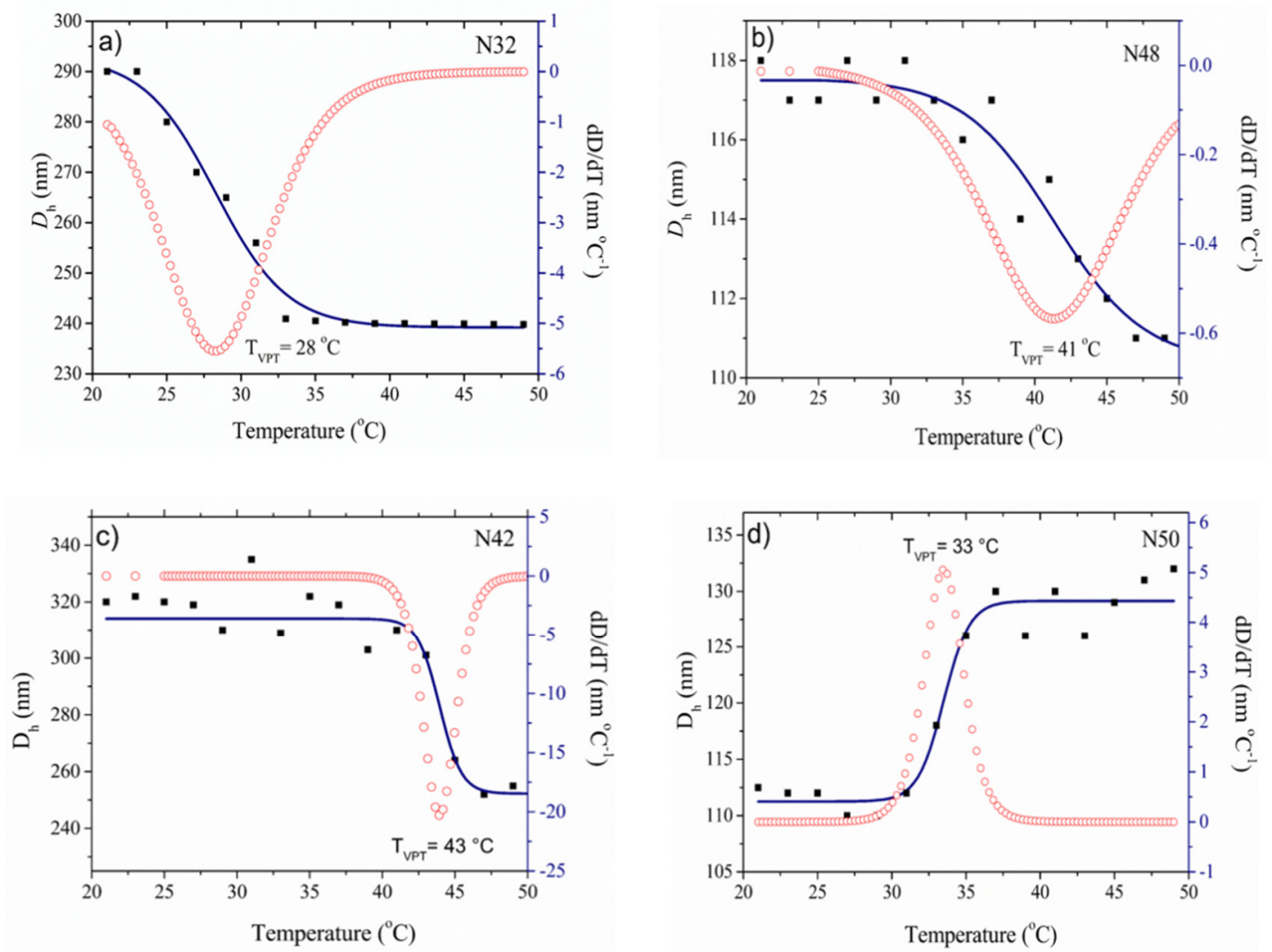

Figure 6. Nanogels size analysis as a function of temperature by DLS: (a) NVCL $60 \mathrm{wt} \%: \mathrm{PEGMA}_{40 \mathrm{wt}} \%$ (N32), (b) NVCL $52 w t \%: P^{2}$ CMA $_{35 w t \%}: 6-\mathrm{ABG}_{13 \mathrm{wt} \%}$ (N48), (c) NVCL $46 \mathrm{wt} \%: \mathrm{PEGMA}_{31 \mathrm{wt} \%}: \mathrm{GAL}_{23 \mathrm{wt} \%}(\mathrm{~N} 42)$, (d) $\mathrm{NVCL}_{46 \mathrm{wt} \%}-\mathrm{PEGMA}_{31 \mathrm{wt} \%}-\mathrm{LAMA}_{23 \mathrm{wt} \%}$ (N50).

In the family of SFEP nanogels containing protected GAL-monomer (galactosylated core), N48 (Figure 6b), N45 (Figure S23 in SM) and N46 (Figure S24 in SM), the transition temperature shows values of 41,44 and $46{ }^{\circ} \mathrm{C}$, respectively, with increase in content on the protected GAL-monomer (6-ABG) of 23.8, 27.2 and $28.1 \mathrm{~mol} \%$. These results can be attributed to the effect to mixing the protected GAL-monomer and $\mathrm{N}$-vinylcaprolactam in the nanogel core. Despite being 6-ABG less hydrophilic in comparison to LAMA, the increase in $\mathrm{T}_{\mathrm{VPT}}$ suggests that more energy is needed to trigger the shrinkage of this type of nanogels I, due to the relative large amount on this GAL-monomer, more than $20 \mathrm{~mol} \%$ in the nanogels as compared to less than $8 \mathrm{~mol} \%$ in the case of LAMA (see composition data 
in Table 2). On the other hand, nanogels synthesized with LAMA monomer (galactosylated interface), N50 (Figure 6d) and N51 (Figure S25 in SM), showed an aggregation behavior opposed to shrinkage; the first one with a small increase in size of $20 \mathrm{~nm}$ approximately, while the nanogel N51 aggregates to very large microparticles (1200 nm approximately). Values of $\mathrm{T}_{\mathrm{VPT}}$ were 33 and $32{ }^{\circ} \mathrm{C}$ respectively. It is an interesting observation that these nanogels were the smallest prepared (radii below $60 \mathrm{~nm}$ ), with the lowest content on GAL monomer from 5.7 to $7.7 \mathrm{~mol} \%$ (Table 2). Since the thermosensitivity of PNVCL is related to a phase transition of polymer chains from soluble to non-soluble in water, it is not surprising that aggregates are formed by heating. Cases where the nanogels shrink without aggregation, is attributed to the shell of the nanogels, which has a moderate shielding effect to prevent it. It is reported in literature that aggregation of lightly crosslinked NVCL-nanogels is not uncommon [10].

The surface charge of the nanogels was estimated through the zeta potential by DLS. Figure 7 shows the $\mathrm{pH}$ dependence of zeta potential for the synthesized nanogels. All nanogels show a negative zeta potential at $\mathrm{pH} \geq 6$, while nanogels $\mathrm{N} 32, \mathrm{~N} 46$ and $\mathrm{N} 45$ show negative zeta potential even at $\mathrm{pH} 5$. It is important to mention that the free-radical initiators used for nanogels preparation have acid groups that are ionized at $\mathrm{pH}$ values $\geq 5$. These groups remain attached to the nanogels surface after initiation of polymerization. Furthermore, the presence of a reducing sugar in galactose monomers may influence the surface charge of the nanogel. Otherwise stated, by increasing the $\mathrm{pH}$ of the dispersion, the sugars are mostly in their reducing form, which also implies a greater presence of -OH groups. Nanogels N42, $\mathrm{N} 44, \mathrm{~N} 48, \mathrm{~N} 50$ and N51 have their isoelectric point (no charge) between $\mathrm{pH} 5$ and 6 . The results indicate that the hydrophilic chains containing GAL and PEGMA stabilize the nanogels in aqueous solution at room temperature. Similar results, where the zeta potential decreases to negative values while the $\mathrm{pH}$ increases, have been observed also in nanometric systems with other oligosaccharides [55-57]. The fact that these nanogels are anionic at physiological $\mathrm{pH}$ may be advantageous for its application in drug delivery systems since a cationic charge at $\mathrm{pH} 7.4$ is usually related to cytotoxicity toward cell-lines [58].

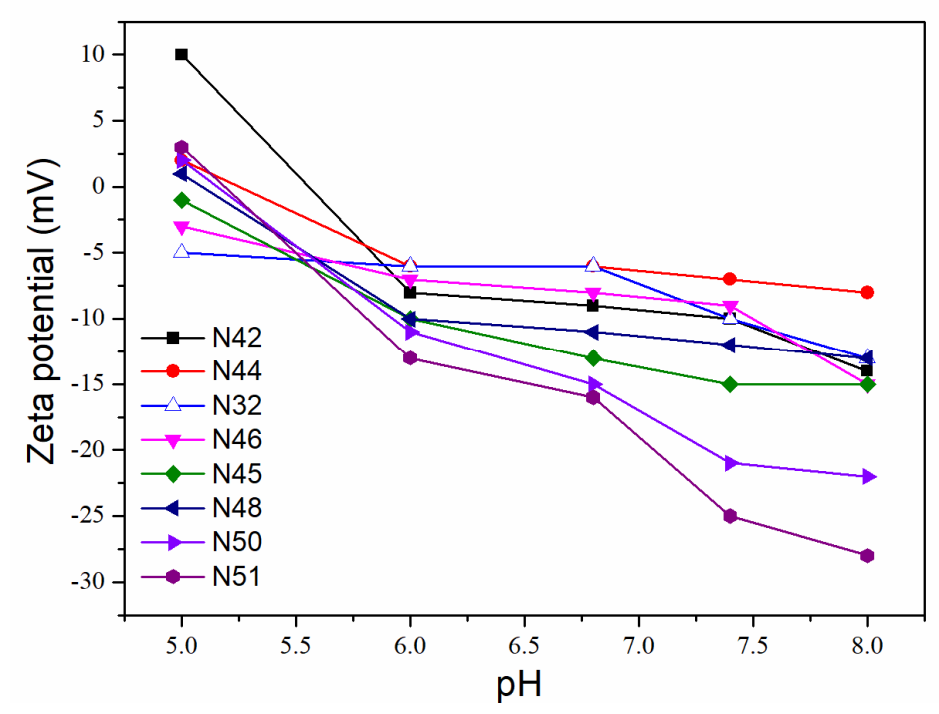

Figure 7. Zeta potential of nanogels at different $\mathrm{pH}$-values.

\section{Conclusions}

A series of nanogels with cross-linked PNVCL core and a shell of PEGMA and galactofunctionalized core, shell or interface, were prepared in water via SFEP using a free radical or RAFT polymerization mechanism. The incorporation of a GAL monomer (LAMA macro-CTA by SFEP/RAFT; and LAMA/6-ABG monomers by SFEP/free radical) allowed to increase the transition temperature of PNVCL/PEGMA nanogels from $28^{\circ} \mathrm{C}$ to values around the relevant physiological temperatures (37-41 ${ }^{\circ} \mathrm{C}$ ). In general, the nanogels obtained, possess spheroidal shape with diameters between 90 and 370 
$\mathrm{nm}$ in their swollen state and GAL-content from 5 to $28 \mathrm{wt} \%$. Nanogels I, containing higher amounts of protected GAL-moieties in the core resemble a hyperbranched semi-spherical particle, according to DLS results, and showed the highest change in $\mathrm{T}_{\mathrm{VPT}}$ with GAL content. Nanogels II containing less GAL moieties in the core/shell interface resemble a spherical core-shell particle with less impact on its $\mathrm{T}_{\mathrm{VPT}}$ values. Nanogels III containing intermediate amounts of GAL-moieties, but in this case as chains in the shell, also resemble a spherical core-shell particle, while their impact on the $\mathrm{T}_{\mathrm{VPT}}$ is also intermediate. These materials have a great potential for drug delivery in cancer treatment, due to their temperature response, small sizes, potential non-cytotoxicity evolving from its constituents, and the potential recognition of cancer cells via the Galactan-Galectin 3 interaction. The effect of location of the GAL moiety in the nanogels towards the recognition of Galectin 3, remains as a goal for future studies.

Supplementary Materials: The following are available online at http://www.mdpi.com/2073-4360/12/9/2150/s1, Figure S1: FT-IR spectra of lactobionic acid and LAMA monomer, Figure S2: ${ }^{1} \mathrm{H}-\mathrm{NMR}$ spectrum of LAMA monomer, Figure S3: Berry plot by SLS analysis of nanogel N42, Figure S4: Berry plot by SLS analysis of nanogel N44, Figure S5: Berry plot by SLS analysis of nanogel N32, Figure S6: Berry plot by SLS analysis of nanogel N50, Figure S7: Berry plot by SLS analysis of nanogel N51, Figure S8: Berry plot by SLS analysis of nanogel N46, Figure S9: Berry plot by SLS analysis of nanogel N48, Figure S10: TEM micrograph of nanogel N42 taken at 80 $\mathrm{KeV}$, Figure S11: TEM-micrograph of nanogels N32 taken at $80 \mathrm{KeV}$, Figure S12: TEM micrograph of nanogels N50 taken at $80 \mathrm{KeV}$, Figure S13: TEM-micrograph of nanogels N48 taken at $80 \mathrm{KeV}$, Figure S14: TEM micrograph of nanogels N45 taken at $80 \mathrm{KeV}$, Figure S15: ${ }^{1} \mathrm{H}-\mathrm{NMR}$ of nanogel N32, Figure S16: ${ }^{1} \mathrm{H}-\mathrm{NMR}$ of nanogel N44, Figure S17: ${ }^{1} \mathrm{H}-\mathrm{NMR}$ of nanogel N46, Figure S18: ${ }^{1} \mathrm{H}-\mathrm{NMR}$ of nanogel N45, Figure S19: ${ }^{1} \mathrm{H}-\mathrm{NMR}$ of nanogel N48, Figure S20: ${ }^{1} \mathrm{H}-\mathrm{NMR}$ of nanogel N50, Figure S21: ${ }^{1} \mathrm{H}-\mathrm{NMR}$ of nanogel N51, Figure S22: $\mathrm{D}_{\mathrm{h}}$ of nanogel N44 as function of temperature obtained by DLS, Figure S23: $D_{h}$ of nanogel N45 as function of temperature obtained by DLS, Figure S24: $D_{h}$ of nanogel N46 as function of temperature obtained by DLS, Figure S25: $D_{h}$ of nanogel N51 as function of temperature obtained by DLS, Scheme S1: Synthesis of PLAMA macro-CTA, Table S1: Reaction conditions for the preparation of nanogels NVCL:PEGMA:GAL using $3 \mathrm{~mol} \%$ of EGDMA with respect to NVCL as crosslinker.

Author Contributions: Formal analysis, J.A.S.-B.; funding acquisition, A.L.-C.; investigation, M.A.G.-A.; methodology, M.A.G.-A.; project administration, A.L.-C.; resources, J.A.S.-B.; supervision, A.L.-C. and J.A.S.-B.; validation, A.L.-C.; visualization, M.A.G.-A.; writing—original draft, M.A.G.-A.; writing-review \& editing, A.L.-C. and J.A.S.-B. All authors have read and agreed to the published version of the manuscript.

Funding: This research was funded by the National Council of Science and Technology of Mexico (CONACYT), grant number CB2016-285419.

Acknowledgments: M.A.G.A. thanks CONACYT for Postdoctoral support. We are grateful to Valentin Miranda (CGIQ, TNM/IT-Tijuana) for ${ }^{1} \mathrm{H}-\mathrm{NMR}$ measurements and to Juan Manuel Martínez (CICESE) for TEM measurements.

Conflicts of Interest: The authors declare no conflict of interest.

\section{References}

1. Spain, S.G.; Gibson, M.I.; Cameron, N.R. Recent advances in the synthesis of well-defined glycopolymers. J. Polym. Sci. Part A Polym. Chem. 2007, 45, 2059-2072. [CrossRef]

2. Werz, D.B.; Seeberger, P.H. Carbohydrates as the next frontier in pharmaceutical research. Chem. Eur. J. 2005, 11, 3194-31206. [CrossRef] [PubMed]

3. Voit, B.; Appelhans, D. Glycopolymers of various architectures-more than mimicking nature. Macromol. Chem. Phys. 2010, 211, 727-735. [CrossRef]

4. Ozyurek, Z.; Franke, K.; Nitschke, M.; Schulze, R.; Simon, F.; Eichhorn, K.J.; Pompe, T.; Werner, C.; Voit, B. Sulfated glyco-block copolymers with specific receptor and growth factor binding to support cell adhesion and proliferation. Biomaterials 2009, 30, 1026-1035. [CrossRef] [PubMed]

5. Muthukrishnan, S.; Nitschke, M.; Gramm, S.; Ozuyrek, Z.; Voit, B.; Werner, C.; Muller, A.H. Immobilized hyperbranched glycoacrylate films as bioactive supports. Macromol. Biosci. 2006, 6, 658-666. [CrossRef]

6. Ogata, M.; Hidari, K.I.P.J.; Kozaki, W.; Murata, T.; Hiratake, J.; Park, E.Y.; Suzuki, T.; Usui, T. Molecular design of spacer- $N$-linked sialoglycopolypeptide as polymeric inhibitors against influenza virus infection. Biomacromolecules 2009, 10, 1894-1903. [CrossRef]

7. Miyagawa, A.; Kasuya, M.C.Z.; Hatanaka, K. Inhibitory effects of glycopolymers having globotriose and/or lactose on cytotoxicity of Shiga toxin 1. Carbohydr. Polym. 2007, 67, 260-264. [CrossRef] 
8. Shmidt, T.; Janik, I.; Kadlubowski, S.; Ulanski, P.; Rosiak, J.M.; Reichelt, R.; Arndt, K.F. Pulsed electron beam irradiation of dilute aqueous poly(vinyl methyl ether) solutions. Polymer 2005, 46, 9908-9918. [CrossRef]

9. Kwon, J.; Drumright, R.; Siegwart, D. The development of micro-gels/nanogels for drug delivery applications. Prog. Polym. Sci. 2008, 33, 448-477.

10. Siirilä, J.; Hietala, S.; Ekholm, F.S.; Tenhu, H. Glucose and maltose surface-functionalized thermoresponsive poly( $N$-vinylcaprolactam) nanogels. Biomacromolecules 2020, 21, 955-965. [CrossRef]

11. Schofield, C.L.; Haines, A.H.; Field, R.A.; Russell, D.A. Silver and gold glyconanoparticles for colorimetric bioassays. Langmuir 2006, 22, 6707-6711. [CrossRef] [PubMed]

12. Hakomori, S. Carbohydrate-carbohydrate interaction as an initial step in cell recognition. Pure Appl. Chem. 1991, 63, 473-482. [CrossRef]

13. de la Fuente, J.M.; Barrientos, A.G.; Rojas, T.C.; Rojo, J.; Cañada, J.; Fernandez, A.; Penade's, S. Gold glyconanoparticles as water-soluble polyvalent models to study carbohydrate interactions. Angew. Chem. Int. Ed. Engl. 2001, 40, 2257-2261. [CrossRef]

14. Rojo, J.; Morales, J.C.; Penade's, S. Carbohydrate-carbohydrate interactions in biological systems. Top. Curr. Chem. 2002, 218, 45-92.

15. de la Fuente, J.M.; Eaton, P.; Barrientos, A.G.; Menendez, M.; Penade's, S. Thermodynamic evidence for $\mathrm{Ca}^{2+-}$ mediated self-aggregation of Lewis $\mathrm{X}$ gold glyconanoparticles. A model for cell adhesion via carbohydrate-carbohydrate interaction. J. Am. Chem. Soc. 2005, 127, 6192-6197. [CrossRef]

16. Carvalho de Souza, A.; Halkes, K.M.; Meeldijk, J.D.; Verkleij, A.J.; Vliegenhart, J.F.G.; Kamerling, J.P. Gold glyconanoparticles as probes to explore the carbohydrate-mediated self-recognition of marine sponge cells. ChemBioChem 2005, 6, 828-831. [CrossRef]

17. Wang, L.Y.; Li, P.; Zhuang, J.; Bai, F.; Feng, J.; Yang, X.; Li, Y. Carboxylic acid enriched nanospheres of semiconductor nano-rods for cell imaging. Angew. Chem., Int. Ed. 2008, 47, 1054-1057. [CrossRef]

18. van Kasteren, S.I.; Campbell, S.J.; Serres, S.; Anthony, D.C.; Sibson, N.R.; Davis, B.G. Glyconanoparticles allow pre-symptomatic in vivo imaging of brain disease. Proc. Natl. Acad. Sci. USA 2009, 106, 18-23. [CrossRef]

19. Dong, C.M. Glyconanoparticles for biomedical applications. Comb. Chem. High Throughput Screen. 2011, 14, 173-181. [CrossRef]

20. Ojeda, R.; de Paz, J.L.; Barrientos, A.G.; Martin-Lomas, M.; Penade's, S. Preparation of multifunctional glyconanoparticles as a platform for potential carbohydrate-based anticancer vaccines. Carbohydr. Res. 2007, 342, 448-449. [CrossRef]

21. Wang, J.D.; Matyjaszewski, K. Controlled/"living" radical polymerization. atom transfer radical polymerization in the presence of transition-metal complexes. J. Am. Chem. Soc. 1995, 117, 5614-5615. [CrossRef]

22. Moad, G.; Rizzardo, E.; Thang, S.H. Living radical polymerization by the RAFT Process. Aust. J. Chem. 2005, 58, 379-410. [CrossRef]

23. Perrier, S.; Takolpuckdee, P. Macromolecular design via reversible addition-fragmentation chain transfer (RAFT)/xanthates (MADIX) polymerization. J. Polym. Sci. Part A Polym. Chem. 2005, 43, 5347. [CrossRef]

24. Moad, G.; Rizzardo, E.; Thang, S.H. Living radical polymerization by the RAFT Process-A First Update. Aust. J. Chem. 2006, 59, 669-692. [CrossRef]

25. Toyoshima, M.; Miura, Y. Preparation of glycopolymer-substituted gold nanoparticles and their molecular recognition. J. Polym. Sci. Part A Polym. Chem. 2009, 47, 1412-1421. [CrossRef]

26. Ting, S.R.S.; Gregory, A.M.; Stenzel, M.H. Polygalactose containing nanocages: The RAFT process for the synthesis of hollow sugar balls. Biomacromolecules 2009, 10, 342-352. [CrossRef]

27. Dong, C.; Chaikof, E.L. Self-assembled nanostructures of a biomimetic glycopolymer-polypeptide triblock copolymer. Colloid Polym. Sci. 2005, 283, 1366-1370. [CrossRef]

28. Cameron, N.R.; Spain, S.G.; Kingham, J.A.; Weck, S.; Albertin, L.; Barker, C.A.; Battaglia, G.; Smart, T.; Blanazs, A. Synthesis of well-defined glycopolymers and some studies of their aqueous solution behavior. Faraday Discuss. 2008, 139, 359-368. [CrossRef]

29. Das, D.; Patra, P.; Ghosh, P.; Rameshbabu, A.P.; Dhara, S.; Pal, S. Dextrin and poly(lactide)-based biocompatible and biodegradable nanogel for cancer targeted delivery of doxorubicin hydrochloride. Polym. Chem. 2016, 7, 2965-2975. 
30. Roy, R.; Tropper, F.D.; Romanowska, A. Custom-designed glycopolymer syntheses by terpolymerizations. J. Chem. Soc. Chem. Commun. 1992, 21,1611-1613. [CrossRef]

31. Glinskii, O.V.; Sud, S.; Mossine, V.V.; Mawhinney, T.P.; Antho-ny, D.C.; Glinsky, G.V.; Pienta, K.J.; Glinsky, V.V. Inhibition of prostate cancer bone metastasis by synthetic TF antigen mim-ic/galectin-3 inhibitor lactulose-L-leucine. Neoplasia 2012, 14, 65-73. [CrossRef] [PubMed]

32. Nangia-Makker, P.; Hogan, V.; Honjo, Y.; Baccarini, S.; Tait, L. Inhibition of human cancer cell growth and metastasis in nude mice by oral intake of modified citrus pectin. J. Natl. Cancer Inst. 2002, 24, 1854-1862. [CrossRef] [PubMed]

33. Inohara, H.; Raz, A. Effects of natural complex carbohydrate (citrus pectin) on murine melanoma cell properties related to galec-tin-3 functions. Glycoconjugate J. 1994, 11, 527-532. [CrossRef] [PubMed]

34. Chauhan, D.L.; Li, G.; Podar, K.; Hideshima, T.; Neri, P.; He, D.; Mitsiades, N.; Richardson, P.; Chang, Y.; Schindler, J.; et al. A novel carbohydrate-based therapeutic GCS-100 overcomes bortezomib resitance and multiple myeloma cells. Cancer Res. 2005, 65, 8350-8358. [CrossRef]

35. Johnson, K.D.; Glinskii, O.V.; Mossine, V.V.; Turk, J.R.; Mawhinney, T.P.; Anthony, D.C.; Henry, C.J.; Huxley, V.H.; Glinsky, G.V.; Pienta, K.J.; et al. Galectin-3 as a potential therapeutic target in tumors arising from malignant endo-thelia. Neoplasia 2007, 9, 662-670. [CrossRef]

36. Wang, H.; Shen, W.; Chang, Y.; Liu, G.; Cao, A.; An, Z. Bio-compatible, Antifouling, and Thermosensitive Core-Shell Nanogels Synthesized by RAFT Aqueous Dispersion Polymerization. Macromolecules 2011, 44, 2524-2530.

37. Duan, C.; Gao, J.; Zhang, D.; Jia, L.; Liu, Y.; Zheng, D.; Liu, G.; Tian, X.; Wang, F.; Zhang, Q. Galactose-decorated $\mathrm{pH}$-responsive nanogels for hepatoma targeted delivery of oridin. Biomacromolecules 2011, 12, 4335-4343. [CrossRef]

38. Quan, S.; Wang, Y.; Zhou, A.; Kumar, P.; Narain, R. Galactose-based thermosensitive nanogels for targeted drug delivery of Iodoazomycin Arabinofuranoside (IAZA) for theranostic management of hypoxic hepatocellular carcinoma. Biomacromolecules 2015, 16, 1978-1986. [CrossRef]

39. Wang, Y.; Hong, C.Y.; Pan, C.Y. Galactose-based amphiphilic block copolymers: Synthesis, micellization, and bioapplication. Biomacromolecules 2013, 14, 1444-1451. [CrossRef]

40. Cortez-Lemus, N.A.; Licea-Claverie, A. Poly(N-vinylcaprolactam), a comprehensive review on a thermoresponsive polymer becoming popular. Prog. Polym. Sci. 2016, 53, 1-51. [CrossRef]

41. Gonzalez-Ayon, M.A.; Cortez-Lemus, N.A.; Zizumbo- Lopez, A.; Licea-Claverie, A. Nanogels of poly( $N$-vinylcaprolactam) core and polyethyleneglycol shell by surfactant free emulsion polymerization. Soft Mater. 2014, 12, 315-325. [CrossRef]

42. Sun, L.; Wei, H.; Zhang, X.; Meng, C.; Kang, G.; Ma, W.; Ma, L.; Wang, B.; Yu, C. Synthesis of polymeric micelles with dual-functional sheddable PEG stealth for enhanced tumor-targeted drug delivery. Polym. Chem. 2020, 11, 4469-4476. [CrossRef]

43. Gonzalez-Ayon, M.A.; Sañudo-Barajas, J.A.; Picos-Corrales, L.A.; Licea-Claverie, A. PNVCL-PEGMA nanohydrogels with tailored transition temperature for controlled delivery of 5-fluorouracil. J. Polym. Sci. Part A Polym. Chem. 2015, 53, 2662-2672. [CrossRef]

44. Moad, G.; Chong, Y.K.; Postma, A.; Rizzardo, E.; Thang, S.H. Advances in RAFT polymerization: The synthesis of polymers with defined end-groups. Polymers 2005, 46, 8458-8468. [CrossRef]

45. Narain, R.; Armes, S.P. Synthesis and aqueous solution properties of novel sugar methacrylate-based homopolymers and block copolymers. Biomacromolecules 2003, 4, 1746-1758. [CrossRef]

46. Figg, C.A.; Simula, A.; Gebre, K.A.; Tucker, B.S.; Haddleton, D.M.; Sumerlin, B.S. Polymerization-induced thermal self-assembly (PITSA). Chem. Sci. 2015, 6, 1230-1236. [CrossRef]

47. Serrano-Medina, A.; Cornejo-Bravo, J.M.; Licea-Claverıe, A. Synthesis of $\mathrm{pH}$ and temperature sensitive, core-shell nano/microgels, by one pot, soap-free emulsion polymerization. J. Colloid Interface Sci. 2012, 369, 82-90. [CrossRef]

48. Manzanares-Guevara, L.A.; Angel Licea-Claverie, A.; Paraguay-Delgado, F. Preparation of stimuli responsive nanogels based on poly $(N, N$-diethylaminoethyl methacrylate) by a simple "surfactant-free" methodology. Soft Mater. 2018, 16, 37-50. [CrossRef]

49. Lou, S.; Gao, S.; Wang, W.; Zhang, M.; Zhang, J.; Wang, C.; Li, C.; Kong, D.; Zhao, Q. Galactose-functionalized multi-responsive nanogels for hepatoma-targeted drug delivery. Nanoscale 2015, 7, 3137-3146. [CrossRef] 
50. Picos-Corrales, L.A.; Licea-Claverıe, A.; Arndt, K.F. Bisensi-tive core-shell nanohydrogels by e-beam irradiation of micelles. React. Funct. Polym. 2014, 75, 31-40. [CrossRef]

51. Picos-Corrales, L.A.; Licea-Claverıe, A.; Arndt, K.F. Core-shell nanogels by RAFT crosslinking polymerization: Synthesis and characterization. J. Polym. Sci. Part A Polym. Chem. 2012, 50, 4277-4287. [CrossRef]

52. Burchard, W. Solution properties of branched macromolecules. Adv. Polym. Sci. 1999, 143, 113-194.

53. Shah, Z.S.; Pal, A.; Gude, R.; Devi, S. Synthesis and characterization of thermo-responsive copolymeric nanoparticles of poly(methyl methacrylate-co-N-vinylcaprolactam). Eur. Polym. J. 2010, 46, 958-967. [CrossRef]

54. Sugihara, S.; Kanaoka, S.; Aoshima, S. thermosensitive random copolymers of hydrophilic and hydrophobic monomers obtained by living cationic copolymerization. Macromolecules 2004, 37, 1711-1749. [CrossRef]

55. Li, X.; Ge, S.; Yang, J.; Chang, R.; Liang, C.; Xiong, L.; Zhao, M.; Li, M.; Sun, Q. Synthesis and study the properties of StNPs/gum nanoparticles for salvianolic acid B-oral delivery system. Food Chem. 2017, 229, 111-119. [CrossRef]

56. Dai, Q.; Zhu, X.; Abbas, S.; Karangwa, E.; Zhang, X.; Xia, S.; Feng, B.; Jia, C. Stable nanoparticles prepared by heating electrostatic complexes of whey protein isolate-dextran conjugate and chondroitin sulfate. J. Agric. Food Chem. 2015, 63, 4179-4189. [CrossRef]

57. Li, J.; Yu, S.; Yao, P.; Jiang, M. Lysozyme-dextran core-shell nanogels prepared via a green process. Langmuir 2008, 24, 3486-3492. [CrossRef]

58. Hwang, T.L.; Aljuffali, I.A.; Lin, C.F.; Chang, Y.T.; Fang, J.Y. Cationic additives in nanosystems activate cytotoxicity and inflammatory response of human neutrophils: Lipid nanoparticles versus polymeric nanoparticles. Int. J. Nanomed. 2015, 10, 371-385.

(C) 2020 by the authors. Licensee MDPI, Basel, Switzerland. This article is an open access article distributed under the terms and conditions of the Creative Commons Attribution (CC BY) license (http://creativecommons.org/licenses/by/4.0/). 